\title{
Increased Extracellular Glutamate In the Nucleus Accumbens Promotes Excessive Ethanol Drinking in Ethanol Dependent Mice
}

\author{
William C Griffin III*,', Harold L Haun', Callan L Hazelbaker', Vorani S Ramachandra' and \\ Howard C Becker ${ }^{1,2,3}$ \\ 'Charleston Alcohol Research Center, Department of Psychiatry and Behavioral Science, Medical University of South Carolina, Charleston, SC, \\ USA; '2Department of Neurosciences, Medical University of South Carolina, Charleston, SC, USA; ${ }^{3}$ Ralph H Johnson VA Medical Center, \\ Charleston, SC, USA
}

\begin{abstract}
Using a well-established model of ethanol dependence and relapse, this study examined adaptations in glutamatergic transmission in the nucleus accumbens (NAc) and their role in regulating voluntary ethanol drinking. Mice were first trained to drink ethanol in a free-choice, limited access ( $2 \mathrm{~h} /$ day) paradigm. One group (EtOH mice) received repeated weekly cycles of chronic intermittent ethanol (CIE) exposure with intervening weeks of test drinking sessions, whereas the remaining mice (CTL mice) were similarly treated but did not receive CIE treatment. Over repeated cycles of CIE exposure, EtOH mice exhibited significant escalation in drinking (up to $\sim 3.5 \mathrm{~g} / \mathrm{kg}$ ), whereas drinking remained relatively stable at baseline levels $(2-2.5 \mathrm{~g} / \mathrm{kg})$ in CTL mice. Using in vivo microdialysis procedures, extracellular glutamate $\left(G L U_{E X}\right)$ levels in the NAc were increased approximately twofold in EtOH mice compared with CTL mice, and this difference was observed 7 days after final CIE exposure, indicating that this hyperglutamatergic state persisted beyond acute withdrawal. This finding prompted additional studies examining the effects of pharmacologically manipulating GLU $U_{E X}$ in the NAc on ethanol drinking in the CIE model. The non-selective glutamate reuptake antagonist, threo- $\beta$-benzyloxyaspartate (TBOA), was bilaterally microinjected into the NAc and found to dose-dependently increase drinking in nondependent (CTL) mice to levels attained by dependent (EtOH) mice. TBOA also further increased drinking in $\mathrm{EtOH}$ mice. In contrast, reducing glutamatergic transmission in the NAc via bilateral injections of the metabotropic glutamate receptor-2/3 agonist LY379268 reduced drinking in dependent (EtOH) mice to nondependent (CTL) levels, whereas having a more modest effect in decreasing ethanol consumption in CTL mice. Taken together, these data support an important role of glutamatergic transmission in the NAc in regulating ethanol drinking. Additionally, these results indicate that ethanol dependence produces adaptations that favor elevated glutamate activity in the NAc which, in turn, promote excessive levels of ethanol consumption associated with dependence.
\end{abstract}

Neuropsychopharmacology (2014) 39, 707-717; doi:I0.1038/npp.2013.256; published online 23 October 2013

Keywords: ethanol; dependence; glutamate; drinking; microdialysis; mouse

\section{INTRODUCTION}

Alcoholism is a chronic relapsing disease. Prolonged excessive alcohol (ethanol) consumption can lead to the development of dependence, which is characterized by a host of neuroadaptive changes in the brain reward and stress systems (Hansson et al, 2008; Koob and Le Moal, 2008; Spanagel, 2009). These changes are thought to underlie expression of withdrawal symptoms when drinking is terminated, increase vulnerability to relapse, and facilitate

*Correspondence: Dr WC Griffin III, Charleston Alcohol Research Center, Department of Psychiatry and Behavioral Science, MSC 861, Medical University of South Carolina, Charleston, SC 29425-0742, USA, Tel: +843 792 4324, Fax: +843792 7353,

E-mail: griffinw@musc.edu

Received II March 2013; revised 2 August 2013; accepted 12 August 2013; accepted article preview online 26 September 2013 a shift from regulated drinking to less controlled and more excessive ethanol consumption (Becker, 2008; Heilig et al, 2010; Vengeliene et al, 2009).

The interaction of ethanol with ionotropic and metabotropic glutamate receptor systems in the brain is known to have a significant role in mediating a variety of acute pharmacological effects of ethanol, and neuroadaptive changes in glutamate activity following chronic ethanol exposure contribute to tolerance and dependence (Gass and Olive, 2008). Although a role for glutamate activity in mediating ethanol drinking, particularly in the context of dependence, is not fully understood, evidence from preclinical and clinical investigations suggests that glutamate transmission may significantly contribute to motivational processes that regulate ethanol consumption. For example, NMDA glutamate receptor antagonism has been reported to mimic the subjective stimulus (intoxicating) 
effects of ethanol in humans (Krystal et al, 2003), monkeys (Vivian et al, 2002), and rodents (Hodge et al, 2006), and animal studies have shown that metabotropic glutamate receptor-5 (mGluR5) activity in the nucleus accumbens (NAc) has a key role in mediating this effect (Besheer et al, 2009). The NAc is a critical brain structure involved in regulating motivated behaviors, and it is an important site for ethanol-glutamate interactions. Microdialysis studies in mice and rats indicate that systemic administration of ethanol alters glutamate levels in NAc, with the effect dependent on the genotype and ethanol dose (Kapasova and Szumlinski, 2008; Melendez et al, 2005). Additionally, blockade of metabotropic glutamate receptors in the NAc attenuates ethanol reinforcement and/or drinking (Cozzoli et al, 2012; Gass and Olive, 2009), suggesting that glutamate signaling in this structure has a role in the maintenance of ethanol consumption.

Adaptive upregulation of glutamate activity following chronic ethanol treatment is well-documented in animal studies (Gass and Olive, 2008). Microdialysis studies in rats have revealed elevated extracellular levels of glutamate following chronic ethanol treatment in several brain regions including dorsal striatum, NAc, and hippocampus (Dahchour and De Witte, 2003; Dahchour et al, 2000; Rossetti and Carboni, 1995). Similarly, in rat studies involving magnetic resonance spectroscopy (MRS) analyses, increased glutamate activity has been noted in the prefrontal cortex (Hermann et al, 2012) and basal ganglia (Gu et al, 2013; Zahr et al, 2009). This aligns with recent MRS studies in human alcoholics that show elevated glutamate activity in anterior cingulate and the NAc (Bauer et al, 2013; Hermann et al, 2012). However, it is important to note that in all these studies, glutamate activity was examined during the acute withdrawal period. Whether the noted increase in glutamate activity following chronic ethanol exposure persists beyond acute withdrawal and what impact this effect may have in relation to drinking is not known.

We have developed a mouse model of ethanol dependence and relapse drinking that involves repeated cycles of chronic ethanol exposure and withdrawal periods and produces significant escalation of voluntary alcohol drinking in dependent compared with nondependent mice (Becker, 2008; Becker and Lopez, 2004; Griffin et al, 2009b; Lopez and Becker, 2005). Given that chronic ethanol induces significant alterations in glutamate activity in several brain regions, and adaptive changes in glutamate transmission have been postulated to have a significant role in the addiction process (Kalivas, 2009), our mouse model of dependence and relapse drinking would appear ideal for examining the relationship between dependence-related adaptations in glutamate activity and increased alcohol consumption. Thus, the present series of studies were conducted to investigate the role of glutamatergic transmission in the NAc in mediating/promoting escalation of drinking associated with ethanol dependence. It was hypothesized that disruption of accumbal glutamate homeostasis induced by dependence significantly contributes to increased propensity to engage in excessive alcohol drinking behavior in dependent compared to nondependent subjects.

\section{MATERIALS AND METHODS}

\section{Subjects}

Male C57BL/6J mice (10 weeks of age) were obtained from Jackson Laboratories (Bar Harbor, ME), individually housed, and maintained in an AAALAC accredited animal facility under a $12 \mathrm{~h}$ light cycle (lights on 0200 hours). Mice had free access to food and water at all times. All experimental protocols were approved by the Institutional Animal Care and Use Committee at the Medical University of South Carolina and were consistent with the guidelines of the NIH Guide for the Care and Use of Laboratory Animals (NIH Publication No. 80-23, revised 1996). Mice were acclimated to the vivarium for 4 weeks before the experiments.

\section{General Study Design}

Mice were given access to ethanol using a 2-bottle choice, limited access procedure (described below). After establishing stable (baseline) ethanol intake, mice were separated into chronic ethanol exposure/withdrawal (EtOH) and control (CTL) groups. The EtOH group received chronic intermittent exposure to ethanol vapor in inhalation chambers ( $16 \mathrm{~h} /$ day for 4 days), whereas CTL mice were similarly handled, but placed in control chambers (see below). Limited access drinking sessions were suspended during inhalation exposure. After inhalation treatment, mice entered a $72 \mathrm{~h}$ abstinence period and then were tested for voluntary ethanol intake for 5 consecutive days using limited access conditions as before. This pattern of weekly chronic intermittent ethanol (CIE) (or air) exposure alternating with 5-day limited access drinking sessions was repeated for four (microdialysis experiments) or five cycles (microinjection experiments). Microdialysis procedures were conducted on the fifth day of Test Cycle 4. Dialysate samples were collected for $90 \mathrm{~min}$ to determine baseline levels of extracellular glutamate $\left(\mathrm{GLU}_{\mathrm{EX}}\right)$. Mice were then administered either 1 or $2 \mathrm{~g} / \mathrm{kg}$ ethanol by gavage and dialysate samples were collected for $135 \mathrm{~min}$. Collection of dialysate samples both before and following ethanol gavage were conducted $\sim 18-20 \mathrm{~h}$ after the previous day's limited access drinking session. In separate studies, microinjection procedures were conducted on the third or fourth day of Test Cycles 3-5. In these experiments, mice were provided the opportunity to drink ethanol in the 2-bottle choice limited access situation following microinjection of pharmacological agents (see below for more details).

\section{Limited Access Drinking Procedures}

Mice were trained to drink ethanol in the home cage under a limited access, 2-bottle choice situation as previously described (Becker and Lopez, 2004; Griffin et al, 2009a; Griffin et al, 2009b; Lopez and Becker, 2005). A modified sucrose fading procedure was used, with $15 \%(\mathrm{v} / \mathrm{v})$ ethanol as the final solution along with tap water as the alternative fluid. The 2-h drinking sessions started at 1330 hours Monday through Friday. The amount consumed was recorded daily $( \pm 0.1 \mathrm{ml})$ and body weights were recorded 
weekly. The position of ethanol and water bottles were alternated randomly to avoid side preferences.

\section{CIE Exposure Procedures}

CIE (or air) vapor exposure was delivered in Plexiglas inhalation chambers as previously described (Becker and Lopez, 2004; Griffin et al, 2009b). Chamber ethanol concentrations were monitored daily and air flow was adjusted to maintain ethanol concentrations within a range that yielded stable blood ethanol levels throughout exposure $(175-225 \mathrm{mg} / \mathrm{dl})$. Mice were placed in inhalation chambers at 1600 hours and removed 16-h later at 0800 hours. Before each 16-h exposure during CIE treatment, EtOH mice were administered ethanol $(1.6 \mathrm{~g} / \mathrm{kg} ; 8 \% \mathrm{w} / \mathrm{v})$ and the alcohol dehydrogenase inhibitor pyrazole $(1 \mathrm{mmol} / \mathrm{kg})$ to maintain a stable level of intoxication during each cycle of ethanol vapor exposure (Griffin et al, 2009a). CTL mice were handled similarly, but received injections of saline and pyrazole before being placed in control chambers. All injections were given intraperitoneally in a volume of $20 \mathrm{ml} / \mathrm{kg}$ body weight.

\section{Stereotaxic Surgery}

Mice were anesthetized using isoflurane mixed with medical-grade air ( $4 \%$ induction, $2 \%$ maintenance), given a subcutaneous injection of $5 \mathrm{mg} / \mathrm{kg}$ carprofen (Pfizer), and placed in a Kopf stereotaxic instrument with digital display (Model 942). For microdialysis experiments, unilateral guide cannulae (CMA/7; CMA Microdialysis, Sweden) were positioned above the NAc (relative to Bregma: AP + 1.7, ML \pm 0.8 , and DV -3.7). For microinjection studies, bilateral guide cannulae (Plastics One; Roanoke, VA) were positioned above the NAc (relative to Bregma: AP +1.7, ML \pm 0.75 , and DV -3.9 ). In both cases, guides were secured to the skull using a light-cured resin system and the guide obdurators remained in place until use (Griffin et al, 2009b). Mice were allowed a minimum of 10 days to recover from surgery before starting an experiment.

\section{Microdialysis Procedures}

As previously described (Griffin et al, 2009b; Griffin et al, 2007), microdialysis probes (CMA/7) were implanted the day before sample collection and aCSF was perfused through the probe during the overnight period at $0.2 \mu \mathrm{l} / \mathrm{min}$ (probes extended $1 \mathrm{~mm}$ beyond the guide cannulae). The next day, the flow was increased to $1 \mu \mathrm{l} / \mathrm{min}$ and allowed to equilibrate for $2 \mathrm{~h}$ before beginning the serial dialysate collection in $15 \mathrm{~min}$ intervals. An aliquot $(10 \mu \mathrm{l})$ of each sample was immediately frozen on dry ice and stored at $-80^{\circ} \mathrm{C}$ until analysis.

\section{Glutamate Determination}

Glutamate was quantified in dialysate samples using isocratic high-performance liquid chromatography with fluorescence detection. Samples were stored in the cooling tray $\left(8{ }^{\circ} \mathrm{C}\right)$ of a Shimadzu SIL-10AF autosampler and derivatized in a 3 min reaction with the addition of $30 \mu \mathrm{l}$ of a solution containing $O$-phthaldehyde ( $10 \mathrm{mg} \%$; dissolved first in $1 \mathrm{ml} 100 \%$ methanol and added to $29 \mathrm{ml}$ of OPA Diluent (Pickering Laboratories)) mixed with $100 \%$ betamercaptoethanol in a 1:2000 ratio. Sample separation was accomplished using an ESA HR- $80 \times 3.2$ column with 120 micron pore size (ESA; Chelmsford, MA). The mobile phase was $0.1 \mathrm{M}$ Sodium Phosphate Dibasic ( $\mathrm{pH}$ 6.75) mixed with $28 \%$ methanol and continuously pumped at $0.5 \mathrm{ml} / \mathrm{min}$ using a Shimadzu LC-20AD Prominence pump. A Shimadzu RF-10XL Fluorescence Detector was set with emission wavelength at $348 \mathrm{~nm}$ and an excitation wavelength at $450 \mathrm{~nm}$. Glutamate concentrations were determined against external standards using peak heights determined by LabSolutions Software (Shimadzu, LC solution Version 1.22 SP1). The limit of detection for this assay is $\sim 25 \mathrm{nM}$ and the limit of quantification is $\sim 135 \mathrm{nM}$.

\section{Microinjection Procedures}

Microinjections were administered on Wednesday or Thursday, $30 \mathrm{~min}$ before the test drinking sessions. Mice were removed from their home cage and gently restrained to insert the bilateral injectors, which extended $0.5 \mathrm{~mm}$ beyond the end of the guides. DL-Threo- $\beta$-benzyloxyaspartate (TBOA) and LY379268 were diluted in phosphatebuffered saline (vehicle) and delivered in a volume of $0.25 \mu \mathrm{l}$ over $2 \mathrm{~min}$ with an additional $2 \mathrm{~min}$ for diffusion using Harvard Apparatus Pump 11 (Harvard Apparatus, Holliston, MA). Doses of the drugs (including vehicle) were administered in a quasi-randomized design, with animals receiving 1, 2, or 3 injections (no animal received more than three microinjections and each injection was separated by 2 weeks). Thus, the factor Dose was treated as a betweensubjects variable in analysis of these data.

\section{Dual Dialysis/Microinjection Guide Implants and Procedures}

The implant was constructed by positioning a single microinjector guide (Plastics One) at approximately an $8^{\circ}$ angle next to a CMA/7 dialysis guide so that when the injection cannula was inserted the tip was within 50 microns of the middle of the active membrane. This was accomplished by using fine grit sandpaper to shave the walls of both guides at slight angles. The proximity of the guide tips was adjusted by additional sanding if necessary and distances were checked under a $\times 10$ microscope with a micron reticle. The two guides along with a piece of wire used to tether the mouse to the fluid swivel were secured together using epoxy glue. Microdialysis procedures were similar to that described above. After collecting baseline samples, the mouse was removed from the cage and gently restrained. The microdialysis probe remained in place while the injector was inserted. Vehicle (phosphate-buffered saline), TBOA, and LY379268 were injected as described above and, after completing the injection procedure, the injector was removed and collection resumed.

\section{Histology}

Microdialysis probe and microinjector placements were verified at the end of each study and only mice with correct placements were included in the final analysis. Briefly, at the 
end of the study, mice were killed by anesthetic overdose and transcardiac perfusion, and the brains were extracted and preserved in $10 \%$ formalin. The brains were sectioned on a crytostat and stained with cresyl violet. For microdialysis, mice were excluded from analysis if the probe was determined to be $<70 \%$ in the NAc. Microinjector placements were determined by measuring $0.5 \mathrm{~mm}$ beyond the most ventral point of the guide cannula track. The reference atlas was (Paxinos and Franklin, 2001).

\section{Drugs}

DL-TBOA and LY379268 were purchased from Tocris Bioscience (Bristol, UK). A $10 \times$ phosphate-buffered saline stock was purchased from Fisher and diluted 1:10 for use as a vehicle for the microinjection studies. TBOA and LY37928 were frozen as 2.5 and $10 \mathrm{mM}$ stocks, respectively, in $1 \times$ PBS and diluted as needed for microinjection.

\section{Statistical Analysis}

Analyses were conducted with SPSS (Version 19) using Student's $t$-test or two-way analysis of variance (ANOVA) with repeated measures, as appropriate. Significant interactions were followed up using Bonferroni corrected pair-wise comparisons. For all analyses, significance was set at $P<0.05$.

\section{RESULTS}

\section{Effects of CIE Exposure on Ethanol Drinking}

Repeated cycles of CIE exposure produced significant escalation of voluntary ethanol consumption over successive test periods compared with relatively stable levels of intake displayed by nondependent controls throughout the study (Figure 1). A two-way repeated measures ANOVA supported this impression by revealing a significant

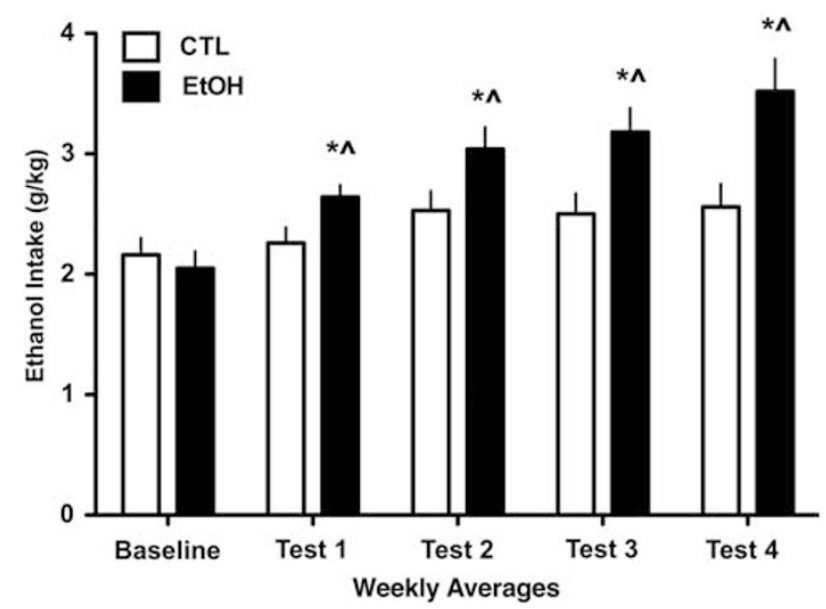

Figure I Escalation of ethanol drinking in dependent (chronic intermittent ethanol, ClE-exposed) mice compared with relatively stable ethanol intake in nondependent controls. The data shown are weekly averages (means $\pm \mathrm{SEM}$ ) for ethanol consumption $(\mathrm{g} / \mathrm{kg})$ during Baseline and Test cycles for $\mathrm{EtOH}$ and $\mathrm{CTL}$ groups. ${ }^{*} P<0.05$ significantly different from $C T L$ group; $\wedge P<0.05$ significantly different from respective baseline level.
Group $\times$ Test Cycle interaction $(\mathrm{F}(4,132)=4.14, P<0.01)$. Post hoc analyses indicated that Baseline ethanol intake was similar for $\mathrm{EtOH}$ mice $(2.0 \pm 0.1 \mathrm{~g} / \mathrm{kg})$ and CTL mice $(2.1 \pm 0.1 \mathrm{~g} / \mathrm{kg})$ and, whereas consumption only slightly increased above baseline levels for CTL mice, ethanol consumption significantly escalated in CIE-exposed (EtOH) mice above their baseline level of intake as well as amount consumed by the CTL group (intake reaching $3.3 \pm 0.2 \mathrm{~g} / \mathrm{kg}$ in EtOH mice compared with $2.5 \pm 0.2 \mathrm{~g} / \mathrm{kg}$ in CTL mice during Test Cycle 4) ( $p$-values $<0.05)$.

\section{$\mathrm{GLU}_{\mathrm{EX}}$ Concentrations in the NAc of Ethanol-Dependent and Nondependent Mice}

Conventional microdialysis procedures were used to examine $\mathrm{GLU}_{\mathrm{EX}}$ in the NAc at the end of Test 4 (1 week after completing the final cycle of CIE (or air) exposure and at least $18 \mathrm{~h}$ after the last limited access drinking session). Glutamate concentrations $(\mu \mathrm{M})$ recovered in NAc dialysate samples were serially collected during a $1.5 \mathrm{~h}$ (six samples) baseline period and then for an additional $2.25 \mathrm{~h}$ (nine samples) following intragastric intubation of either 1 or $2 \mathrm{~g} / \mathrm{kg}$ ethanol. As can be seen, baseline $\mathrm{GLU}_{\mathrm{EX}}$ dialysate concentrations were consistently greater (approximately twofold) in EtOH mice compared with CTL mice (Figure 2a). A three-way repeated measures ANOVA of these baseline data revealed a significant main effect of Group $(\mathrm{F}(1,31)=7.79, P<0.005)$. The effects of Dose and Time were not significant, and these factors did not interact with the main effect of Group (Fs $<1.0)$. Baseline data were analyzed further by collapsing over Dose and Time factors. This analysis also indicated that $\mathrm{GLU}_{\mathrm{EX}}$ dialysate concentrations were significantly greater in EtOH compared with CTL mice $(\mathrm{t}(33)=2.83, P<0.005)$ (Figure $2 \mathrm{~b}$ ).

Analysis of $\mathrm{GLU}_{\mathrm{EX}}$ levels in dialysate samples collected after mice were challenged by gavage of 1 or $2 \mathrm{~g} / \mathrm{kg}$ ethanol using a two-way repeated measures ANOVA revealed a significant main effect of Group $(\mathrm{F}(1,31)=3.29, P<0.0001)$. Similar to the analysis of baseline samples, Dose and Time factors were not significant and these factors did not significantly influence the Group effect of EtOH mice displaying higher $\mathrm{GLU}_{\mathrm{EX}}$ levels than CTL mice (all Fs $<2.4, p$-values $>0.1$ ) (Figure 2a).

To further evaluate the potential effects of administering 1 or $2 \mathrm{~g} / \mathrm{kg}$ ethanol on $\mathrm{GLU}_{\mathrm{EX}}$ levels in the NAc, each subject's data were transformed to a percentage of its average baseline value and the data were analyzed separately for the two ethanol doses. For mice treated with $1 \mathrm{~g} / \mathrm{kg}$ ethanol, a twoway repeated measures ANOVA revealed no significant effects of Group, Time, or the Group $\times$ Time interaction (F's $<1.4, p$-values $>0.1$ ) (Figure 2c). Analysis of samples collected from separate groups of mice gavaged with $2 \mathrm{~g} / \mathrm{kg}$ ethanol indicated a significant main effect of Time $(\mathrm{F}(9,171)=2.03, \quad P<0.05)$, consistent with the modest increase in $\mathrm{GLU}_{\mathrm{EX}}$ levels exhibited in both EtOH and CTL mice that returned to baseline levels within $1 \mathrm{~h}$. However, a main effect of Group and the Group $\times$ Time interaction were not significant $(\mathrm{Fs}<1.0)$ (Figure $2 \mathrm{~d})$. Thus, even when accounting for baseline differences in $\mathrm{GLU}_{\mathrm{EX}}$ levels between EtOH and CTL groups, neither 1 nor $2 \mathrm{~g} / \mathrm{kg}$ doses of ethanol administered by gavage significantly altered $\mathrm{GLU}_{\mathrm{EX}}$ concentrations in the NAc. 

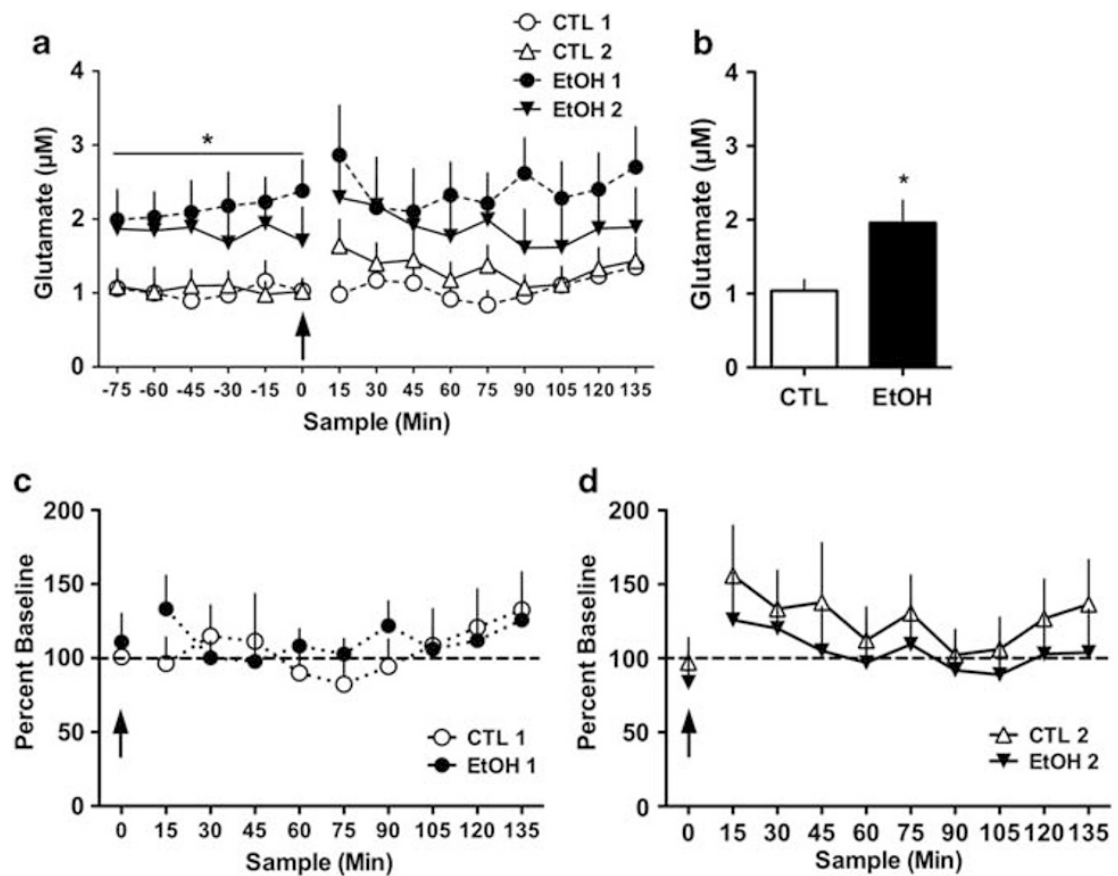

Figure 2 Extracellular glutamate concentrations in dialysate samples from NAc of ethanol dependent (EtOH) and nondependent (CTL) mice collected at baseline and after administration of I or $2 \mathrm{~g} / \mathrm{kg}$ ethanol gavage. (a) Extracellular glutamate $\left(G L U_{E x} ; M\right)$ levels were approximately twofold higher in EtOH $(n=19)$ compared with CTL $(n=16)$ mice. Analysis indicated that EtOH mice displayed significantly higher baseline of GLU EX levels than CTL mice, but there was no effect of ethanol gavage in either group or either dose. $* P<0.05$ significantly differs from $C T L$ values. (b) Significantly higher baseline $G L U_{E X}$ levels in $\mathrm{EtOH}$ mice compared with CTL mice was confirmed by expressing data collapsed across Dose and Time factors. *P<0.05 significantly differs from CTL group. (c) Administering I g/kg ethanol by gavage did not alter $\mathrm{GLU}_{\mathrm{EX}}$ levels in either EtOH or CTL groups of mice; data are expressed as percent of average baseline values for $\mathrm{EtOH}$ and $\mathrm{CTL}$ groups. (d) Administration of $2 \mathrm{~g} / \mathrm{kg}$ ethanol by gavage did not significantly alter $\mathrm{GLU} \mathrm{Ex}_{\mathrm{E}}$ levels in either EtOH or CTL groups; data are expressed as percent of average baseline values for EtOH and CTL groups.

\section{Microinjection of the Non-Selective Glutamate Uptake Inhibitor DL-TBOA into the NAc of Ethanol-Dependent and Nondependent Mice}

Given the observed elevation in baseline levels of accumbal extracellular glutamate in EtOH mice compared with CTL mice, it is possible that higher glutamatergic tone in the NAc may have a role in promoting/driving escalation of drinking displayed in dependent mice. To test this hypothesis, the non-selective glutamate transporter inhibitor TBOA was injected into the NAc to examine whether pharmacologically increasing glutamate activity in this brain region increases ethanol consumption in the CIE relapse drinking model. As expected, CIE exposure produced increased voluntary ethanol drinking in ethanoldependent (EtOH) mice compared with nondependent control (CTL) mice over two test cycles of drinking. This was supported by a significant Group $\times$ Test Cycle interaction in the two-way repeated measures ANOVA $(\mathrm{F}(2,134)=13.30, P<0.001)$. Post hoc analyses indicated that EtOH mice consumed significantly more ethanol during Test 1 and Test 2 compared with both their baseline level of intake and the amount consumed by CTL mice ( $p$ values $<0.05$ ). Baseline intake was similar for $\mathrm{EtOH}$ and CTL groups (Figure 3a). Intra-NAc injections of TBOA 30 min before limited access $(2 \mathrm{~h})$ drinking sessions during Test Cycles 3-5 increased ethanol consumption in a doserelated manner in EtOH and CTL groups (Figure $3 \mathrm{~b}$ ). The two-way ANOVA revealed main effects of Group $(\mathrm{F}(1,83)=4.86, \quad P<0.05) \quad$ and Dose $\quad(\mathrm{F}(2,83)=14.43$,
$P<0.0001$ ), but the Group $\times$ Dose interaction did not achieve statistical significance. Thus, blockade of glutamate transporters in NAc increased voluntary ethanol drinking in nondependent mice to levels exhibited by vehicle-treated dependent mice, and this manipulation also further elevated drinking in dependent mice.

Microinjection of the mGluR2/3 Agonist LY379268 into the NAc of Ethanol-Dependent and Nondependent Mice

This study examined whether reducing presynaptic glutamate release in the NAc via microinjection of the mGluR2/3 agonist LY379268 would reduce ethanol drinking in EtOH and CTL groups. Analysis of drinking behavior during Baseline, Test 1, and Test 2 (before microinjections) using a two-way repeated measures ANOVA indicated a significant Group $\times$ Test Cycle interaction $(\mathrm{F}(2,116)=17.26$, $P<0.0001)$. Post hoc analyses found that ethanol drinking was greater in EtOH mice during Test 1 and Test 2 relative to their baseline intake and intake in CTL mice ( $p$ values $<0.05$ ). CTL mice also showed a relatively small, yet significant increase in drinking during Test 2 compared with their baseline level of consumption $(P<0.05)$ (Figure 4a). Analysis of the effects of intra-NAc injection of LY379268 on drinking during Test Cycles 3-5 using a two-way ANOVA revealed a significant main effect of Dose $(\mathrm{F}(4,66)=9.68, P<0.001)$ and a significant Group $\times$ Dose interaction $(\mathrm{F}(4,66)=3.40, P<0.01)$. Post hoc comparisons indicated that the three highest doses of the mGluR2/3 

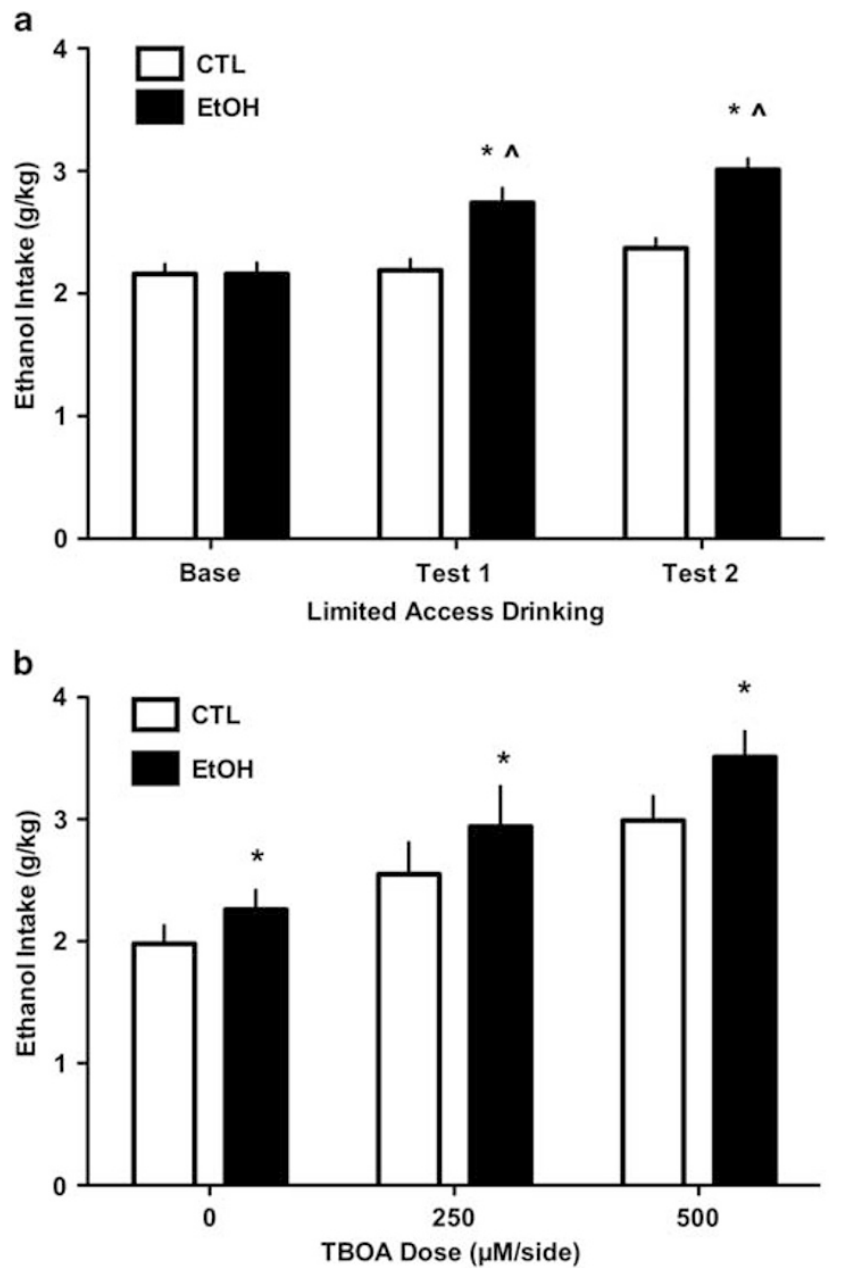

Figure 3 Effects of pharmacologically increasing extracellular glutamate $\left(G L U_{E X}\right)$ levels in NAc via microinjection of the non-selective glutamate transporter blocker threo- $\beta$-benzyloxyaspartate (TBOA) on voluntary ethanol drinking in dependent and nondependent mice. (a) Ethanol consumption $(\mathrm{g} / \mathrm{kg})$ significantly increased over successive chronic intermittent ethanol (CIE) exposure cycles in $\mathrm{EtOH}$ mice $(n=30)$ compared with CTL mice $(n=39)$ before intra-NAc TBOA treatment. $* P<0.05$ significantly different from $C T L$ group; ${ }^{\wedge} P<0.05$ significantly different from respective baseline level. (b) Bilateral microinjection of TBOA 30 min before limited access drinking sessions increased voluntary ethanol consumption in a dose-related manner in both $\mathrm{CTL}$ and $\mathrm{EtOH}$ groups. $* P<0.05$ significantly differs from $C T L$ group; $\wedge$ P $<0.05$ significantly differs from vehicle condition. Values are means \pm SEM.

agonist significantly reduced voluntary ethanol intake relative to vehicle in $\mathrm{EtOH}$ mice $(P<0.05)$. In contrast, although there was an apparent dose-dependent trend for reduced ethanol intake in CTL mice, this effect did not achieve statistical significance (Figure 4b). These data suggest that ethanol-dependent mice are more sensitive than nondependent mice to the effects of intra-NAc LY379268 administration on ethanol drinking.

\section{Effects of Microinjecting TBOA and LY379268 on GLU $\mathrm{EX}_{\mathrm{E}}$ in the NAc}

To confirm that intra-NAc injection of TBOA and LY379268 produced the expected increase and decrease in $\mathrm{GLU}_{\mathrm{EX}}$ a

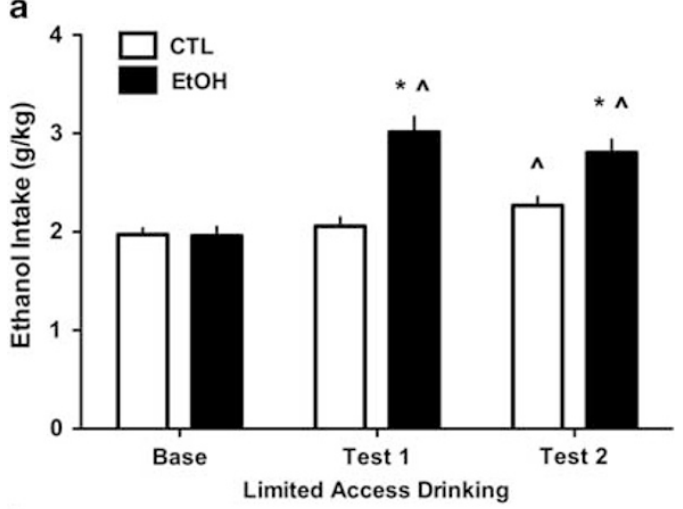

b

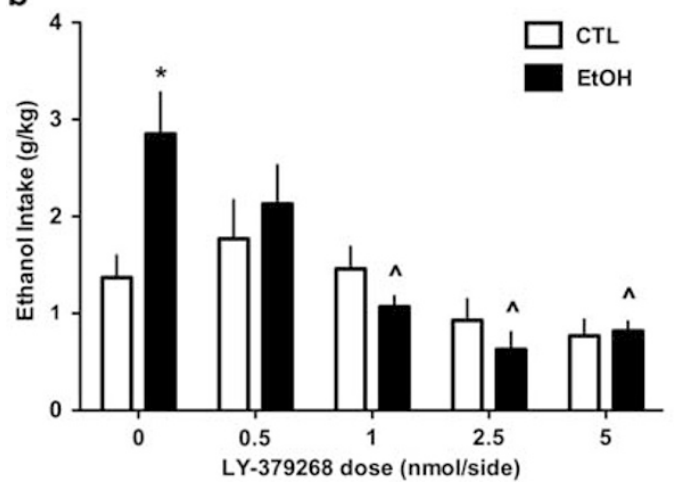

Figure 4 Effects of pharmacologically reducing extracellular glutamate $\left(G L U_{E X}\right)$ levels in NAc via microinjection of the metabotropic glutamate receptor-2/3 (mGluR2/3) agonist LY379268 on voluntary ethanol drinking in dependent and nondependent mice. (a) Ethanol consumption $(\mathrm{g} / \mathrm{kg})$ significantly increased over successive chronic intermittent ethanol (CIE) exposure cycles in $\mathrm{EtOH}$ mice $(n=23)$ compared to CTL mice $(n=37)$ prior to intra-NAc LY379268 treatment. $* P<0.05$ significantly different from $C T L$ group; $\wedge P<0.05$ significantly different from respective baseline level. (b) Bilateral microinjection of LY379268 given 30 min before limited access drinking sessions decreased voluntary ethanol consumption in a dose-related manner in $\mathrm{EtOH}$ mice while producing a modest (nonsignificant) reduction in ethanol intake in CTL mice. $* P<0.05$ significantly differs from $C T L$ group; $\wedge P<0.05$ significantly differs from respective vehicle condition. Values are means \pm SEM.

levels, respectively, the microinjector was positioned adjacent to the microdialysis probe (see Materials and methods). Results indicated that compared with vehicle injection, TBOA $(500 \mu \mathrm{M})$ increased extracellular glutamate for about $30 \mathrm{~min}$, whereas LY379268 (5 nmol) robustly reduced $\mathrm{GLU}_{\mathrm{EX}}$ levels over the entire $90 \mathrm{~min}$ collection period (Table 1). This was supported by a two-way repeated measures ANOVA, with the average value from three samples collected before injection serving as the baseline point (Time $=0 \mathrm{~min}$ ). The analysis indicated significant main effects of Drug $(\mathrm{F}(2,13)=3.55, P=0.027)$ and Time $(\mathrm{F}(12,78)=3.199, P=0.008)$ as well as a significant Drug $\times$ Time interaction $(\mathrm{F}(12,78)=2.590, P=0.006)$. Post hoc pair-wise comparisons indicated that TBOA increased $\operatorname{GLU}_{\mathrm{EX}}(\sim 100 \%)$ above baseline levels at $15 \mathrm{~min}(91 \%)$ and $30 \mathrm{~min}(25 \%)$, with values returning to baseline during the remainder of the collection period. In contrast, LY379268 significantly reduced GLU $\mathrm{EX}_{\mathrm{E}}$ below baseline levels starting at $30 \mathrm{~min}(71 \%)$, with the reduction sustained (76$81 \%$ ) over the $90 \mathrm{~min}$ collection period. GLU $\mathrm{EX}$ levels 
registered after vehicle administration did not differ from baseline values throughout the collection period.

\section{Histological Verification of Probes and Injector Tips}

Figures $5 \mathrm{a}$ and $\mathrm{b}$ show representative brain sections stained with cresyl violet indicating placements of microdialysis probes and microinjector tips, respectively. The gray shaded areas in the atlas plates show areas targeted by the dialysis and microinjection experiments (Figure $5 \mathrm{c}$ ). For the dialysis experiment, mice were excluded from the analysis if the microdialysis probe was more than $70 \%$ outside the shaded area. For these experiments, the distribution of placement of dialysis probes within subregions of the NAc is as follows: NAC core (34\%), NAc shell (40\%), and NAc coreshell transition region (25\%). Data analyses did not indicate significance differences in profile of results among these regions. In the microinjector experiments, mice were excluded if one or both tips were outside the shaded area.

\section{DISCUSSION}

Consistent with our previous reports, our mouse model of ethanol dependence and relapse drinking involving repeated cycles of CIE exposure produced significant escalation of voluntary drinking in dependent compared with nondependent mice (Becker and Lopez, 2004; Griffin et al, 2009b; Lopez and Becker, 2005). That is, once stable intake was established under limited access conditions $(2 \mathrm{~h} /$ day $)$, free-choice ethanol consumption progressively increased over testing cycles in CIE-exposed mice, whereas intake remained relatively unchanged in air-exposed controls. This level of increased ethanol consumption attained in the present series of experiments has been previously shown to result in significant elevation (two- to threefold increase) in blood ethanol levels and brain ethanol concentrations (Griffin et al, 2009b). These results (increased alcohol consumption) are congruent with those reported by others using similar procedures in mice (Finn et al, 2007; Dhaher et al, 2008) and rats (Gehlert et al, 2007; Roberts et al, 1996; Roberts et al, 2000; Sommer et al, 2008).

Results from this study also indicated that extracellular concentrations of glutamate $\left(\mathrm{GLU}_{\mathrm{EX}}\right)$ in the NAc were increased approximately twofold in dependent compared with nondependent mice. In general, this finding is consistent with other studies showing increased basal
GLU $_{\mathrm{Ex}}$ in the NAc (Ding et al, 2013; Kapasova and Szumlinski, 2008; Melendez et al, 2005) as well as other brain regions such as hippocampus (Chefer et al, 2011; Dahchour and De Witte, 1999; Moghaddam and Bolinao, 1994) and the amygdala (Roberto et al, 2004). However, results from the present study are unique in two ways. First, although some studies have demonstrated increased basal $\mathrm{GLU}_{\mathrm{EX}}$ levels in the NAc following repeated injections of ethanol (Kapasova and Szumlinski, 2008; Melendez et al, 2005), this study examined this effect in a dependence model where elevated glutamate levels were observed only in dependent mice that exhibited escalation of voluntary drinking. Second, although some reports have indicated elevated accumbal GLU $\mathrm{EX}_{\mathrm{EX}}$ levels following chronic ethanol (vapor inhalation) exposure, these measurements were collected during acute withdrawal (within $24 \mathrm{~h}$ of exposure) (Dahchour and De Witte, 2003; Dahchour et al, 2000).
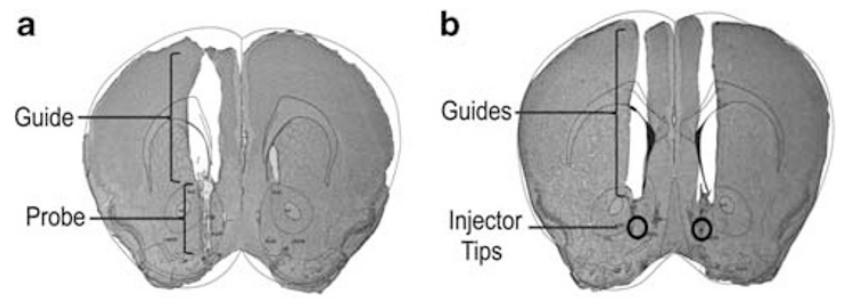

C

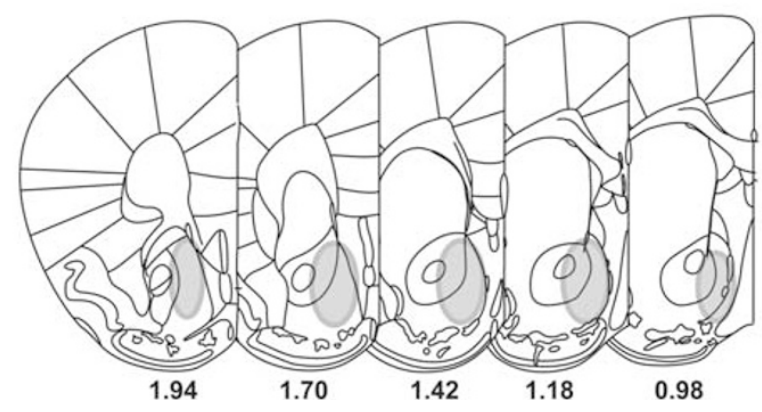

Figure 5 Microdialysis probe and microinjector tip placements in the NAc. Cresyl violet stained tissue sections showing typical placements for microdialysis probes (a) and the bilateral microinjector guides and tips (b). (c) Shaded areas depicted on plates from the atlas of Paxinos and Franklin (200I) indicating the areas where microdialysis probes and microinjection tips were located. Data were not included in analyses if more than $70 \%$ of the dialysis probe or one or both microinjector tips were outside the boundaries of the shaded area.

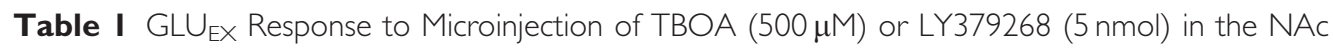

\begin{tabular}{|c|c|c|c|c|c|c|c|}
\hline \multirow[t]{2}{*}{ Drug } & \multicolumn{7}{|c|}{ Time Post Injection (min) } \\
\hline & 0 & 15 & 30 & 45 & 60 & 75 & 90 \\
\hline $\operatorname{TBOA}(n=6)$ & $1.29 \pm 0.15$ & $2.46 \pm 0.41^{\mathrm{a}, \mathrm{b}}$ & $1.61 \pm 0.20^{\mathrm{a}}$ & $1.47 \pm 0.17$ & $1.48 \pm 0.21$ & $1.40 \pm 0.13$ & $1.29 \pm 0.14$ \\
\hline LY379268 $(n=3)$ & $0.89 \pm 0.10$ & $0.96 \pm 0.32$ & $0.26 \pm 0.11^{\mathrm{a}}$ & $0.19 \pm 0.04^{\mathrm{a}, \mathrm{b}}$ & $0.19 \pm 0.03^{\mathrm{a}}$ & $0.17 \pm 0.04^{\mathrm{a}, \mathrm{b}}$ & $0.21 \pm 0.04^{\mathrm{a}}$ \\
\hline
\end{tabular}

Abbreviations: $G L \cup_{E X}$, extracellular glutamate; TBOA, threo- $\beta$-benzyloxyaspartate.

Values are $\mu M$ and expressed as mean \pm SEM.

${ }^{\text {aD }}$ ifferent from baseline $(P<0.05)$.

bDifferent from $V E H$ at the same time point $(P<0.05)$. 
Results from the present study demonstrate increased GLU $_{\mathrm{EX}}$ levels in NAc associated with the CIE exposure model that extend well beyond acute withdrawal (at least 7 days following exposure), suggesting a persistent alteration in glutamatergic activity. Taken together, results from this study suggest a relationship between increased glutamatergic tone in the NAc and the propensity for increased drinking exhibited by ethanol-dependent mice.

Although repeated cycles of CIE exposure produced significant elevation in accumbal GLU $_{\mathrm{EX}}$ levels 7 days following the final CIE exposure, subsequent oral challenge with ethanol ( 1 and $2 \mathrm{~g} / \mathrm{kg}$ ) did not significantly alter $\mathrm{GLU}_{\mathrm{EX}}$ levels in either dependent or nondependent mice. Although there appeared to be a trend to increase $\mathrm{GLU}_{\mathrm{EX}}$ at the higher dose $(2 \mathrm{~g} / \mathrm{kg})$, the lack of a significant response to the ethanol challenge was observed even when differences between the groups in baseline $\mathrm{GLU}_{\mathrm{EX}}$ levels were taken into account. This was somewhat surprising given that other microdialysis studies in mice and rats have indicated systemic administration of low ethanol doses $(0.5-1 \mathrm{~g} / \mathrm{kg})$

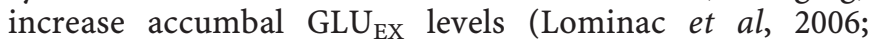
Moghaddam and Bolinao, 1994; Selim and Bradberry, 1996; Smith et al, 2004; Szumlinski et al, 2008), whereas higher doses ( 2 to $3 \mathrm{~g} / \mathrm{kg}$ ) either decrease $\mathrm{GLU}_{\mathrm{EX}}$ or produce no change (Lominac et al, 2006; Piepponen et al, 2002; Smith et al, 2004; Yan et al, 1998). All of these earlier studies administered ethanol via the intraperitoneal route during dialysis, whereas ethanol was administered by gavage in this study. Thus, it is possible that pharmacokinetic differences produced by different routes of administration might contribute to differences in the accumbal $\mathrm{GLU}_{\mathrm{EX}}$ response to acute ethanol challenge. Another possibility is that glutamatergic transmission in some subregions of the NAC may be more responsive to ethanol challenge than others. For example, studies with probe placements largely, but not exclusively, within the NAc shell suggest this subregion responds to ethanol challenge in a dose-dependent manner (Lominac et al, 2006). Analysis of the present data did not reveal differences in $\mathrm{GLU}_{\mathrm{EX}}$ levels across NAc subregions following ethanol gavage. Nevertheless, additional studies will be needed to more fully examine these possibilities. It also will be of interest to determine whether volitional (selfadministered) ethanol induces similar or unique changes in accumbal GLU $\mathrm{EX}_{\text {levels. }}$

Given the apparent sustained elevation in accumbal baseline $\mathrm{GLU}_{\mathrm{EX}}$ levels following CIE exposure, the possibility that this hyperglutamatergic tone in the NAc may be linked with escalated drinking in ethanol-dependent mice prompted additional studies that examined the effects of pharmacologically manipulating extracellular glutamate levels in the NAc on voluntary ethanol consumption. The first approach used DL-TBOA, a non-selective antagonist at the major glutamate reuptake proteins residing in the glial and neuronal membranes, with little affinity for ionotropic and metabotropic glutamate receptors (Shimamoto et al, 1998; Shimamoto et al, 2000). Consistent with this mechanism, TBOA microinjected next to dialysis probes in the NAc was shown to significantly increase GLU $\mathrm{EX}_{\mathrm{EX}}$ levels. Further, bilateral TBOA microinjection into the NAc significantly increased ethanol drinking in a dose-related fashion. It is not clear why the TBOA-induced increase in $\mathrm{GLU}_{\mathrm{EX}}$ levels was evident for about $30 \mathrm{~min}$, returning to baseline levels thereafter. Extracellular glutamate levels are tightly controlled by a number of mechanisms (Danbolt, 2001), and it is likely that such mechanisms were operable in restoring homeostatic glutamate levels. Despite the relatively short-lived increase in GLU $\mathrm{EX}_{\mathrm{E}}$ levels, TBOA produced a clear dose-related increase in amount of ethanol consumed over the 2-h drinking session. Additional studies that track the temporal pattern of ethanol intake following intra-NAc TBOA administration will be required to ascertain whether this pharmacologically induced increased in $\mathrm{GLU}_{\mathrm{EX}}$ levels (even for only $30 \mathrm{~min}$ ) is sufficient to drive increased drinking over a longer period of time.

It is noteworthy that a similar finding has been reported for intra-NAc TBOA effects on ethanol drinking in mice using a modified 24-h drinking paradigm (Kapasova and Szumlinski, 2008). In the present study, the highest dose of TBOA increased ethanol drinking in nondependent mice to levels similar to that measured in ethanol-dependent mice. Thus, despite exhibiting relatively stable levels of intake over several weeks, nondependent mice were induced to drink greater amounts of ethanol that ultimately reached the higher levels of intake displayed by dependent mice when $G_{L} U_{E X}$ levels were elevated in NAc via TBOA injection. Escalated drinking in dependent mice was also further increased by intra-NAc TBOA administration. Thus, these results suggest that increasing glutamatergic activity in the NAc is associated with increased propensity to consume ethanol.

Considering these results, it was predicted that reducing glutamatergic transmission in the NAc would reduce ethanol drinking in the CIE exposure dependence model. Activation of mGluR2 and mGluR3 receptors reduces glutamate release (Cartmell and Schoepp, 2000; Schoepp, 2001), and this effect was verified in the present study when the mGluR2/3 agonist LY37928 was injected next to a dialysis probe implanted in the NAc and found to significantly decrease GLU $\mathrm{EX}_{\text {levels. Intra-NAc LY379268 }}$ administration significantly reduced voluntary ethanol consumption in dependent and nondependent mice in a dose-related manner. This effect was most robust in dependent mice where LY379268 produced a maximal $78 \%$ decrease in ethanol consumption and, importantly, reduced ethanol drinking to levels similar to nondependent mice. Although LY379268 also reduced ethanol intake in nondependent mice, this effect was more modest and did not achieve statistical significance (maximal reduction relative to vehicle $=44 \%$ ). These findings are consistent with other reports showing that systemic administration of LY379268 attenuated ethanol reinforcement, stress-induced ethanol seeking, and conditioned reinstatement, with the most robust effects seen in animals with a history of ethanol dependence (Kufahl et al, 2011; Sidhpura et al, 2010). Because mGluR2/3 receptors are widely expressed in forebrain regions including the NAc (Ohishi et al, 1998; Tamaru et al, 2001), the present findings extend previous studies to specifically include a role for mGluR2/3 receptors in the NAc in regulating voluntary ethanol consumption.

Taken together, results from the present microdialysis and microinjection experiments indicate adaptations in ethanol-dependent mice that contribute to enhanced glutamate transmission in the NAc. However, the mechanism underlying these adaptations and the source of elevated 
glutamatergic activity is not known. Extracellular glutamate levels are tightly regulated by numerous neuronal and glial release and uptake functions. One possibility is that repeated cycles of CIE exposure produce a persistent hyperexcitable state in the NAc driven by increased activity in glutamatergic afferents arising from the prefrontal cortex and limbic (hippocampus and amygdala) nuclei (Britt et al, 2012). In the NAc, mGluR2 and mGluR3 receptors are predominantly located in the neurons, pre- and postsynaptically (Ohishi et al, 1998; Tamaru et al, 2001). These group II metabotropic glutamate receptors are known to function together to reduce glutamate release (Cartmell and Schoepp, 2000; Schoepp, 2001) and dampen neuronal excitability (Lovinger and McCool, 1995). Our finding that LY379268 was more effective in reducing ethanol drinking in dependent mice suggests greater inherent glutamatergic transmission in the NAc of these mice, consistent with the higher $\mathrm{GLU}_{\mathrm{EX}}$ concentrations in the NAc.

Another possibility is that elevated accumbal GLU $\mathrm{EX}_{\mathrm{E}}$ concentrations result from CIE-induced alterations in expression and/or function of excitatory amino-acid transporters (EAATs). EAAT1 (GLAST) and EAAT2 (GTL-1) are predominantly expressed in glia and these sodiumdependent glutamate transporters are critically involved in maintaining low extracellular levels of $\mathrm{GLU}_{\mathrm{EX}}$ in the central nervous system (Amara and Fontana, 2002; Danbolt, 2001; Tzingounis and Wadiche, 2007). Elevated GLU $\mathrm{EX}_{\text {levels in }}$ the NAc following a subchronic ethanol exposure regimen were shown to be associated with the downregulation of sodium-dependent glutamate uptake, but no change in EAAT1 or EAAT2 expression in rats (Melendez et al, 2005). Similarly, reduced glutamate clearance was reported to accompany increased accumbal $\mathrm{GLU}_{\mathrm{EX}}$ concentrations in C57BL/6J mice after repeated ethanol injection treatment (Kapasova and Szumlinski, 2008). In a recent study in alcohol-preferring (P) rats, several weeks of free-choice ethanol consumption produced elevated $\mathrm{GLU}_{\mathrm{EX}}$ levels in NAc that was associated with reduced glutamate clearance and decreased expression of EAAT1 but not EAAT2 (Ding et al, 2013). Thus, altered expression and/or function of EAATs expressed in glia (EAAT1 and EAAT2) and possibly in neurons (EAAT3/EAAC1) following chronic ethanol exposure may contribute to the resultant elevated glutamate activity in NAc. To date, we have not observed differences in EAAT1 or EAAT2 expression in NAc in our CIE exposure model (unpublished findings), but on-going studies are examining the possibility of a functional change in uptake capacity that could contribute to increased accumbal GLU $U_{\mathrm{EX}}$ concentrations. In addition, it is possible that increased glutamate release from glial cells via the cystine-glutamate exchanger may contribute to elevated glutamatergic tone in the NAc and increased propensity to drink, as altered function of this sodium-independent transporter has been implicated in drug addiction (Kalivas, 2009).

Finally, results from the present study indicating dependence-related enhanced glutamate tone in the NAc that is associated with increased drinking may have implications regarding treatment strategies for alcoholism. As noted above, clinical MRS studies have reported increased glutamate activity in anterior cingulate and NAc in abstinent human alcoholics compared with age- and sexmatched healthy controls (Bauer et al, 2013; Hermann et al,
2012). In another MRS study, acamprosate was found to reduce glutamate levels in anterior cingulate several weeks after abstinence (Umhau et al, 2010). Acamprosate is an FDA-approved medication for alcohol dependence that is thought to alter central glutamate neurotransmission, although its mechanism of action is not fully understood and reports on its clinical efficacy in treating alcohol dependence have been mixed (Berger et al, 2013; Mann et al, 2012; Mason and Lehert, 2012; Mann et al 2012; Yahn et al, 2013). Likewise, studies with other therapeutics such as antiepileptics (eg, topiramate, gabapentin, pregabalin, and levetiracetam) that indirectly alter central glutamate activity have produced mixed results in terms of reducing alcohol craving/drinking (De Sousa, 2010; Guglielmo et al, 2012; Johnson and Ait-Daoud, 2010). Clearly, the relationship between dependence, drinking, and glutamate transmission warrants further investigation, especially in the context of identifying new and better pharmacotherapeutics for alcoholism. Indeed, the CIE model of dependence and relapse drinking used in the present study may be particularly valuable for evaluating the efficacy of various pharmacological agents in reducing dependence-related escalated drinking and elevated glutamatergic activity.

In summary, in a model of dependence and relapse drinking, repeated cycles of CIE exposure produced escalation of drinking along with elevated extracellular levels of glutamate in the NAc in dependent compared with nondependent mice. This twofold increase in accumbal $\mathrm{GLU}_{\mathrm{EX}}$ concentrations persisted well beyond acute withdrawal. Further, pharmacologically manipulating glutamatergic tone in the NAc altered ethanol consumption. Increasing $\mathrm{GLU}_{\mathrm{EX}}$ with the non-selective transporter blocker, TBOA, increased drinking in nondependent mice to levels attained by dependent animals, whereas decreasing GLU $_{\mathrm{EX}}$ using the mGluR2/3 agonist, LY379268, significantly reduced drinking in dependent mice to moderate levels exhibited by nondependent mice. Collectively, these results indicate that CIE exposure produces adaptations that favor the elevation of glutamate activity in the NAc, and this hyperglutamatergic state drives and/or promotes increased drinking characteristic of alcohol dependence.

\section{FUNDING AND DISCLOSURE}

This work was supported by NIH grant P50 AA10716 (WCG and HCB), F32 AA021321 (VSR). Dr Becker's research program is funded by $\mathrm{NIH}$ and the Department of Veterans Affairs Medical Research. Dr Becker also has conducted contractual work and served as a consultant for Eli Lilly and Company, but those activities have no relationship to the present report. The authors declare no conflict of interest.

\section{ACKNOWLEDGEMENTS}

We thank Judi S Randall, Michael S Miner, and Laura L Snyder for excellent technical assistance in conducting this work. 


\section{REFERENCES}

Amara SG, Fontana ACK (2002). Excitatory amino acid transporters: keeping up with glutamate. Neurochem Int 41: 313-318.

Bauer J, Pedersen A, Scherbaum N, Bening J, Patschke J, Kugel H et al (2013). Craving in alcohol-dependent patients after detoxification is related to glutamatergic dysfunction in the nucleus accumbens and the anterior cingulate cortex. Neuropsychopharmacology 38: 1401-1408.

Becker HC (2008). Alcohol dependence, withdrawal, and relapse. Alcohol Res Health 31: 348-361.

Becker HC, Lopez MF (2004). Increased ethanol drinking after repeated chronic ethanol exposure and withdrawal experience in C57BL/6 mice. Alcohol Clin Exp Res 28: 1829-1838.

Berger L, Fisher M, Brondino M, Bohn M, Gwyther R, Longo L et al (2013). Efficacy of acamprosate for alcohol dependence in a family medicine setting in the United States: a randomized, double-blind, placebo-controlled study. Alcohol Clin Exp Res 37: 668-674.

Besheer J, Grondin JJ, Salling MC, Spanos M, Stevenson RA, Hodge CW (2009). Interoceptive effects of alcohol require mGlu5 receptor activity in the nucleus accumbens. J Neurosci 29: 9582-9591.

Britt JP, Benaliouad F, McDevitt RA, Stuber GD, Wise RA, Bonci A (2012). Synaptic and behavioral profile of multiple glutamatergic inputs to the nucleus accumbens. Neuron 76: 790-803.

Cartmell J, Schoepp DD (2000). Regulation of neurotransmitter release by metabotropic glutamate receptors. J Neurochem 75: 889-907.

Chefer V, Meis J, Wang G, Kuzmin A, Bakalkin G, Shippenberg T (2011). Repeated exposure to moderate doses of ethanol augments hippocampal glutamate neurotransmission by increasing release. Addict Biol 16: 229-237.

Cozzoli DK, Courson J, Caruana AL, Miller BW, Greentree DI, Thompson $\mathrm{AB}$ et al (2012). Nucleus accumbens mGluR5-associated signaling regulates binge alcohol drinking under drinking-inthe-dark procedures. Alcohol Clin \& Exp Res 36: 1623-1633.

Dahchour A, De Witte P (1999). Effect of repeated ethanol withdrawal on glutamate microdialysate in the hippocampus. Alcohol Clin Exp Res 23: 1698-1703.

Dahchour A, De Witte P (2003). Excitatory and inhibitory amino acid changes during repeated episodes of ethanol withdrawal: an in vivo microdialysis study. Eur J Pharmacol 459: 171-178.

Dahchour A, Hoffman A, Deitrich R, de Witte P (2000). Effects of ethanol on extracellular amino acid levels in high-and lowalcohol sensitive rats: a microdialysis study. Alcohol Alcohol 35: 548-553.

Danbolt NC (2001). Glutamate uptake. Prog Neurobiol 65: 1-105.

De Sousa A (2010). The pharmacotherapy of alcohol dependence: a state of the art review. Mens Sana Monogr 8: 69-82.

Dhaher R, Finn D, Snelling C, Hitzemann R (2008). Lesions of the extended amygdala in C57BL/6J mice do not block the intermittent ethanol vapor-induced increase in ethanol consumption. Alcohol Clin Exp Res 32: 197-208.

Ding ZM, Rodd ZA, Engleman EA, Bailey JA, Lahiri DK, McBride WJ (2013). Alcohol drinking and deprivation alter basal extracellular glutamate concentrations and clearance in the mesolimbic system of alcohol-preferring (P) rats. Addict Biol 18: 297-306.

Finn DA, Snelling C, Fretwell AM, Tanchuck MA, Underwood L, Cole $\mathrm{M}$ et al (2007). Increased drinking during withdrawal from intermittent ethanol exposure is blocked by the CRF receptor antagonist d-Phe-CRF(12-41). Alcohol Clin Exp Res 31: 939-949.

Gass JT, Olive MF (2008). Glutamatergic substrates of drug addiction and alcoholism. Biochem Pharmacol 75: 218-265.

Gass JT, Olive MF (2009). Role of protein kinase C epsilon (PKCvarepsilon) in the reduction of ethanol reinforcement due to mGluR5 antagonism in the nucleus accumbens shell. Psychopharmacology 204: 587-597.
Gehlert DR, Cippitelli A, Thorsell A, Le AD, Hipskind PA, Hamdouchi C et al (2007). 3-(4-Chloro-2-morpholin-4-yl-thiazol5-yl)-8-(1-ethylpropyl)-2,6-dimethyl- imidazo[1,2-b]pyridazine: a novel brain-penetrant, orally available corticotropin-releasing factor receptor 1 antagonist with efficacy in animal models of alcoholism. J Neurosci 27: 2718-2726.

Griffin WC 3rd, Lopez MF, Becker HC (2009a). Intensity and duration of chronic ethanol exposure is critical for subsequent escalation of voluntary ethanol drinking in mice. Alcohol Clin Exp Res 33: 1893-1900.

Griffin WC 3rd, Lopez MF, Yanke AB, Middaugh LD, Becker HC (2009b). Repeated cycles of chronic intermittent ethanol exposure in mice increases voluntary ethanol drinking and ethanol concentrations in the nucleus accumbens. Psychopharmacol 201: 569-580.

Griffin WC 3rd, Middaugh LD, Becker HC (2007). Voluntary ethanol drinking in mice and ethanol concentrations in the nucleus accumbens. Brain Res 1138: 208-213.

Gu M, Zahr NM, Spielman DM, Sullivan EV, Pfefferbaum A, Mayer D (2013). Quantification of glutamate and glutamine using constant-time point-resolved spectroscopy at $3 \mathrm{~T}$. NMR Biomed 26: $164-172$.

Guglielmo R, Martinotti G, Clerici M, Janiri L (2012). Pregabalin for alcohol dependence: a critical review of the literature. Adv Ther 29: 947-957.

Hansson AC, Rimondini R, Neznanova O, Sommer WH, Heilig M (2008). Neuroplasticity in brain reward circuitry following a history of ethanol dependence. Eur J Neurosci 27: 1912-1922.

Heilig M, Egli M, Crabbe JC, Becker HC (2010). Acute withdrawal, protracted abstinence and negative affect in alcoholism: are they linked? Addict Biol 15: 169-184.

Hermann D, Weber-Fahr W, Sartorius A, Hoerst M, Frischknecht U, Tunc-Skarka N et al (2012). Translational magnetic resonance spectroscopy reveals excessive central glutamate levels during alcohol withdrawal in humans and rats. Biol Psychiatry 71: 1015-1021.

Hodge CW, Grant KA, Becker HC, Besheer J, Crissman AM, Platt DM et al (2006). Understanding how the brain perceives alcohol: neurobiological basis of ethanol discrimination. Alcohol Clin Exp Res 30: 203-213.

Johnson BA, Ait-Daoud N (2010). Topiramate in the new generation of drugs: efficacy in the treatment of alcoholic patients. Curr Pharm Des 16: 2103-2112.

Kalivas PW (2009). The glutamate homeostasis hypothesis of addiction. Nature Rev Neuro 10: 561-572.

Kapasova Z, Szumlinski KK (2008). Strain differences in alcoholinduced neurochemical plasticity: a role for accumbens glutamate in alcohol intake. Alcohol Clin Exp Res 32: 617-631.

Koob GF, Le Moal M (2008). Addiction and the brain antireward system. Annu Rev Psychol 59: 29-53.

Krystal JH, Petrakis IL, Mason G, Trevisan L, D’Souza DC (2003). N-methyl-D-aspartate glutamate receptors and alcoholism: reward, dependence, treatment, and vulnerability. Pharmacol Ther 99: 79-94.

Kufahl PR, Martin-Fardon R, Weiss F (2011). Enhanced sensitivity to attenuation of conditioned reinstatement by the mGluR $2 / 3$ agonist LY379268 and increased functional activity of mGluR 2/3 in rats with a history of ethanol dependence. Neuropsychopharmacol 36: 2762-2773.

Lominac KD, Kapasova Z, Hannun RA, Patterson C, Middaugh LD, Szumlinski KK (2006). Behavioral and neurochemical interactions between Group 1 mGluR antagonists and ethanol: Potential insight into their anti-addictive properties. Drug Alcohol Depend 85: 142-156.

Lopez MF, Becker HC (2005). Effect of pattern and number of chronic ethanol exposures on subsequent voluntary ethanol intake in C57BL/6J mice. Psychopharmacology 181: 688-696. 
Lovinger DM, McCool BA (1995). Metabotropic glutamate receptor-mediated presynaptic depression at corticostriatal synapses involves mGLuR2 or 3. J Neurophysiol 73: 1076-1083.

Mason BJ, Lehert P (2012). Acamprosate for alcohol dependence: a sex-specific meta-analysis based on individual patient data. Alcohol Clin Exp Res 36: 497-508.

Mann K, Lemenager T, Hoffmann S, Reinhard I, Hermann D, Batra A et al The PREDICT Study Team (2012). Results of a doubleblind, placebo-controlled pharmacotherapy trial in alcoholism conducted in Germany and comparison with the US COMBINE study. Addict Biol; doi:10.1111/adb.12012 (e-pub ahead of print).

Melendez RI, Hicks MP, Cagle SS, Kalivas PW (2005). Ethanol exposure decreases glutamate uptake in the nucleus accumbens. Alcohol Clin Exp Res 29: 326-333.

Moghaddam B, Bolinao ML (1994). Biphasic effect of ethanol on extracellular accumulation of glutamate in the hippocampus and the nucleus accumbens. Neurosci Lett 178: 99-102.

Ohishi H, Neki A, Mizuno N (1998). Distribution of a metabotropic glutamate receptor, mGluR2, in the central nervous system of the rat and mouse: an immunohistochemical study with a monoclonal antibody. Neurosci Res 30: 65-82.

Paxinos G, Franklin KBJ (2001). The Mouse Brain in Stereotaxic Coordinates 2ndAcademic Press: San Diego, CA, USA.

Piepponen TP, Kiianmaa K, Ahtee L (2002). Effects of ethanol on the accumbal output of dopamine, GABA and glutamate in alcohol-tolerant and alcohol-nontolerant rats. Pharmacol Biochem Behav 74: 21-30.

Roberto M, Schweitzer P, Madamba SG, Stouffer DG, Parsons LH, Siggins GR (2004). Acute and chronic ethanol alter glutamatergic transmission in rat central amygdala: an in vitro and in vivo analysis. J Neurosci 24: 1594-1603.

Roberts AJ, Cole M, Koob GF (1996). Intra-amygdala muscimol decreases operant ethanol self-administration in dependent rats. Alcohol Clin Exp Res 20: 1289-1298.

Roberts AJ, Heyser CJ, Cole M, Griffin P, Koob GF (2000). Excessive ethanol drinking following a history of dependence: animal model of allostasis. Neuropsychopharmacology 22: 581-594.

Rossetti ZL, Carboni S (1995). Ethanol withdrawal is associated with increased extracellular glutamate in the rat striatum. Eur J Pharmacol 283: 177-183.

Schoepp DD (2001). Unveiling the functions of presynaptic metabotropic glutamate receptors in the central nervous system. J Pharmacol Exp Ther 299: 12-20.

Selim M, Bradberry CW (1996). Effect of ethanol on extracellular 5HT and glutamate in the nucleus accumbens and prefrontal cortex: comparison between the Lewis and Fischer 344 rat strains. Brain Res 716: 157-164.

Shimamoto K, Lebrun B, Yasuda-Kamatani Y, Sakaitani M, Shigeri Y, Yumoto N et al (1998). DL-threo-beta-benzyloxyaspartate, a potent blocker of excitatory amino acid transporters. Mol Pharmacol 53: 195-201.

Shimamoto K, Shigeri Y, Yasuda-Kamatani Y, Lebrun B, Yumoto N, Nakajima T (2000). Syntheses of optically pure beta-hydroxyas- partate derivatives as glutamate transporter blockers. Bioorg Med Chem Lett 10: 2407-2410.

Sidhpura N, Weiss F, Martin-Fardon R (2010). Effects of the mGlu2/3 agonist LY379268 and the mGlu5 antagonist MTEP on ethanol seeking and reinforcement are differentially altered in rats with a history of ethanol dependence. Biol Psychiatry 67: 804-811.

Smith A, Watson CJ, Frantz KJ, Eppler B, Kennedy RT, Peris J (2004). Differential increase in taurine levels by low-dose ethanol in the dorsal and ventral striatum revealed by microdialysis with on-line capillary electrophoresis. Alcohol Clin \& Exp Res 28: $1028-1038$

Spanagel R (2009). Alcoholism: a systems approach from molecular physiology to addictive behavior. Physiol Rev 89: 649-705.

Sommer WH, Rimondini R, Hansson AC, Hipskind PA, Gehlert DR, Barr CS et al (2008). Upregulation of voluntary alcohol intake, behavioral sensitivity to stress, and amygdala crhr1 expression following a history of dependence. Biol Psychiatry 63: 139-145.

Szumlinski KK, Ary AW, Lominac KD, Klugmann M, Kippin TE (2008). Accumbens Homer2 overexpression facilitates alcoholinduced neuroplasticity in C57BL/6J mice. Neuropsychopharmacology 33: 1365-1378.

Tamaru Y, Nomura S, Mizuno N, Shigemoto R (2001). Distribution of metabotropic glutamate receptor mGluR3 in the mouse CNS: differential location relative to pre- and postsynaptic sites. Neurosci 106: 481-503.

Tzingounis AV, Wadiche JI (2007). Glutamate transporters: confining runaway excitation by shaping synaptic transmission. Nature Rev Neurosci 8: 935-947.

Umhau JC, Momenan R, Schwandt ML, Singley E, Lifshitz M, Doty L et al (2010). Effect of acamprosate on magnetic resonance spectroscopy measures of central glutamate in detoxified alcohol-dependent individuals: a randomized controlled experimental medicine study. Arch Gen Psychiatry 67: 1069-1077.

Vengeliene V, Celerier E, Chaskiel L, Penzo F, Spanagel R (2009). Compulsive alcohol drinking in rodents. Addict Biol 14: 384-396.

Vivian JA, Waters CA, Szeliga KT, Jordan K, Grant KA (2002). Characterization of the discriminative stimulus effects of $\mathrm{N}$-methyl- D-aspartate ligands under different ethanol training conditions in the cynomolgus monkey (Macaca fascicularis). Psychopharmacology (Berl) 162: 273-281.

Yan QS, Reith ME, Yan SG, Jobe PC (1998). Effect of systemic ethanol on basal and stimulated glutamate releases in the nucleus accumbens of freely moving Sprague-Dawley rats: a microdialysis study. Neurosci Lett 258: 29-32.

Yahn SL, Watterson LR, Olive MF (2013). Safety and efficacy of acamprosate for the treatment of alcohol dependence. Subst Abuse 6: 1-12.

Zahr NM, Mayer D, Vinco S, Orduna J, Luong R, Sullivan EV et al (2009). In vivo evidence for alcohol-induced neurochemical changes in rat brain without protracted withdrawal, pronounced thiamine deficiency, or severe liver damage. Neuropsychopharmacology 34: 1427-1442. 